\title{
HISTÓRIA \\ VÍRUS ZIKA NA HISTÓRIA DAS DOENÇAS: DA MALFORMAÇÃO NA GESTAÇÃO ÀS POLÍTICAS PÚBLICAS NO CAMPO DA SAÚDE REPRODUTIVA DA MULHER \\ Reynaldo José Loio Alves
VÍRUS ZIKA NA HISTÓRIA DAS DOENÇAS: DA MALFORMAÇÃO NA GESTAÇÃO ÀS POLÍTICAS PÚBLICAS NO CAMPO DA SAÚDE REPRODUTIVA DA MULHER

\section{ZIKA VIRUS IN THE HISTORY OF DISEASES: MALFORMATION IN GESTATION TO PUBLIC POLICIES IN THE FIELD OF WOMEN'S REPRODUCTIVE HEALTH}

Reynaldo José Loio Alves ${ }^{1}$

\begin{abstract}
RESUMO:O artigo tem como objetivo analisar elementos presentes em fontes documentais sobre a epidemia de Zika vírus e a ocorrência de microcefalia no Brasil de 2015 à atualidade. Este trabalho discute o problema com base no referencial teórico da historiografia da saúde e história das doenças, de modo que os conceitos abordados contextualizam a etiologia da doença, o contexto epidêmico, as ações estatais, a questão dos direitos da mulher no que tange à saúde reprodutiva, tal como a importância da dimensão social da doença presente nos campos da saúde pública e da ciência. As fontes documentais foram extraídas dos documentos do Ministério da Saúde, que são: o Protocolo de Atenção à saúde e resposta à ocorrência de Microcefalia relacionada à infecção pelo Vírus Zika (2015) e a Cartilha de Informação ao público - Vírus Zika, v. 2 (2016).
\end{abstract}

PALAVRAS-CHAVE: Zika vírus; Saúde reprodutiva da mulher; história.

ABSTRACT: The article aims to analyze elements present in documentary sources about the Zika virus epidemic and the occurrence of microcephaly in Brazil from 2015 to the present time. This paper discusses the problem based on the theoretical reference of the historiography of the health and history of the diseases, so that the concepts covered contextualize the etiology of the disease, the epidemic context, the state actions, the issue of women's health rights Reproductive health, as well as the importance of the social dimension of the present disease in the fields of public health and science. The documentary sources were extracted from documents of the Ministry of Health, which are: the Health Care Protocol and response to the occurrence of Microcephaly related to Zika Virus infection (2015) and the Public Information Booklet - Zika Virus, v. 2 (2016).

KEYWORDS: Zika virus; Reproductive health of women; History.

INTRODUÇÃO

O registro de uma nova doença febril em algumas cidades do Nordeste do Brasil, a partir do primeiro semestre de 2015, trouxe à tona um novo cenário epidêmico, que se agravou devido à ocorrência de microcefalia em bebês, cujas mães foram infectadas pelo vírus Zika durante a gravidez. A emergência desse evento corroborou com novas discussões, desafios e ações em torno da doença, de políticas

\footnotetext{
${ }^{1}$ Mestrando do Programa de Pós-graduação em História das Ciências e da Saúde da Casa de Oswaldo Cruz (PPGHCS/COC-Fiocruz) - Rio de Janeiro.
} 


\section{HISTÓRIA}

VÍRUS ZIKA NA HISTÓRIA DAS DOENÇAS: DA MALFORMAÇÃO NA GESTAÇÃO ÀS POLÍTICAS PÚBLICAS NO CAMPO DA SAÚDE REPRODUTIVA DA MULHER

Reynaldo José Loio Alves

de saúde pública, de discursos e práticas relacionados ao saber médico-científico e ao campo de saúde reprodutiva da mulher.

A proposta deste trabalho é discutir elementos presentes em fontes documentais a fim de constituir argumentos da epidemia de Zika como evento social de importância significativa no contexto político-social. Nesse sentido, essa análise se relaciona com os debates e interpretações historiográficas sobre saúde e doença, num processo que engloba a história das "transformações" nas relações entre saúde, medicina, enfermidades e sociedade.

A conjuntura multifacetada em torno da epidemia do Vírus Zika corrobora com as discussões que vêm sendo reveladas pela historiografia da saúde mais recente. Autores tais como Marcos Cueto e Elisabeth Fee (2006), Charles Rosenberg (1997), Diego Armus (2004; 2014), entre outros, demonstram que fenômenos relacionados à saúde e à doença não são apenas biológicos, mas constituem uma limite tênue com elementos sociais. Diante disso, observamos que a Historiografia ocupa um importante lugar na análise da conjuntura complexa e vivenciada recentemente, tal qual observamos o contorno que a epidemia de Zika vêm constituindo.

É importante salientar que o vírus Zika representa mais que um agente etiológico, que em seu conjunto, só existe enquanto produto social, pois reúne diferentes concepções e práticas científicas, assim como o conflito entre elas. De modo que constituindo-se além de "experimentos" científicos, de políticas de saúde pública, de crenças populares, entre outros fatores.

No que tange a discussão no campo de história das doenças, é importante demarcar alguns aspectos da análise pretendida, a qual busca aproximar-se da dimensão sociocultural, considerando a articulação dos conceitos e fatores que caracterizam a construção social e simbólica da doença (NASCIMENTO, 2005, p. 35), tal como a dimensão social de aspectos no campo da saúde pública, da ciência e da biomedicina.

Ao consideramos diferentes níveis de análises, elucidamos com a perspectiva de Armus (2014, p.37), o qual enfatiza que há distintos níveis de contextualização histórica, sendo eles o dos discursos, das políticas e o da experiência. Desta forma, nos centraremos, especialmente na dimensão dos discursos, e como esses 


\section{HISTÓRIA}

VÍRUS ZIKA NA HISTÓRIA DAS DOENÇAS: DA MALFORMAÇÃO NA GESTAÇÃO ÀS POLÍTICAS PÚBLICAS NO CAMPO DA SAÚDE REPRODUTIVA DA MULHER

Reynaldo José Loio Alves

constituem espaço para a elucidação de políticas públicas, inclusive por meio do desenvolvimento de pesquisas em diferentes instituições científicas.

Além disso, é fundamental salientar que as ações em saúde, tais como, por exemplo, as experiências da sociedade ante a ameaça da doença e as estratégias de combate que se desenvolvem, são fenômenos que devem ser entendidos como complexos e duradouros, até mais que contextos políticos. Assim, é pertinente considerar a abordagem de Hochman e Diego Armus em Cuidar, controlar, curar ensaios históricos sobre a saúde e doença na América Latina e Caribe (2004, p. 18), haja visto que nos chama a atenção para as dimensões socioculturais das enfermidades discutidos anteriormente por diversos autores, onde demonstram que saúde e doença não são apenas ausência ou presença de patógenos. Ao contrário, há uma série de negociações, entre múltiplos atores, para a consolidação daquilo que entendemos enquanto saúde, o que também se aplica às doenças. Nesse contexto, essas negociações possuem desdobramentos específicos, sejam em políticas públicas e/ou privadas em saúde, reformas, revoltas, entre outros.

Corroborando com essa perspectiva, atualmente os estudos de história das doenças no Brasil se ocupam de eventos patológicos específicos, não só em busca de sua definição médico-científica, como também do que chamamos de sua fenomenologia, isto é, o modo de sua incidência em determinados momentos e local (NASCIMENTO, 2014, p. 1).

\section{METODOLOGIA E FONTES}

O trabalho constitui uma visão histórica acerca dos fatores presentes na epidemia de vírus Zika, tal como a ocorrência da microcefalia e a questão dos direitos de saúde reprodutiva da mulher. Sendo assim, busca-se traçar um paralelo entre as informações retiradas das fontes e as questões centrais discutidas em Historiografia da saúde e na História das doenças.

A metodologia se pauta na abordagem qualitativa do problema e o campo de análise se baseia na historiografia da saúde e da doença, articulando a temática a partir de Charles Rosenberg no que se refere ao conceito de doença como diagnóstico do social e as formas de se pensar o papel desta como objeto de inter-relação dos 
VÍRUS ZIKA NA HISTÓRIA DAS DOENÇAS: DA MALFORMAÇÃO NA GESTAÇÃO ÀS POLÍTICAS PÚBLICAS NO CAMPO DA SAÚDE REPRODUTIVA DA MULHER

Reynaldo José Loio Alves

discursos sobre políticas de Estado, responsabilidade médica e culpabilidade individual e das vertentes que discutem saúde e doença por autores como Claudine Herzlich (2004) , Marcus Cueto (2006) e Diego Armus (2004; 2014). Além disso, outros textos serão utilizadas para contextualizar as políticas públicas e o foco da saúde reprodutiva da mulher.

A escolha das fontes se baseou na especificidade de análise e no contexto que articular a história das doenças, as políticas públicas estatais, os saberes médicocientíficos e os conceitos de saúde e doença. A fim de aprofundar a temática proposta, levantou-se alguns elementos no material que reforçam a defesa da hipótese que será desenvolvida no texto, defende-se que o contexto específico do surgimento da doença, isto é, a eclosão da epidemia de Vírus Zika e da sua relação com a ocorrência de síndrome neurológica, tendo a microcefalia como um exemplo que nos permite analisar o (in)sucesso das políticas públicas.

Desse modo, se faz necessário discutir os direitos da saúde reprodutiva da mulher e demonstrar as lacunas "deixadas" pelos documentos e ações do governo sobre o problema, articulando elementos das políticas públicas no que se refere aos dados epidemiológicos, as pesquisas no campo médico-científico, as ações de prevenção (cartilha) e do Protocolo de orientação aos profissionais referente à assistência das mulheres com bebês com microcefalia.

O primeiro campo de reflexão envolve a dimensão médico-científica sobre a etiologia da doença, o(s) vetor(es), as formas de transmissão e a relação entre Zika e a Microcefalia. Nesse caso, extraímos informações da Revista de Manguinhos, de maio de 2016. Sendo assim, percebemos que no material há um rico cenário de análise, em que se articulam a produção e circulação de saberes constituídos por campos de tensões e controvérsias e, que ainda não apresentam conclusões consensuais acerca do problema. Nesse sentido, estão sendo realizados vários estudos sobre o vírus Zika em instituições de pesquisa, tanto a nível nacional como internacional.

A edição 34 da revista aborda a tríplice epidemia e os estudos acerca da problemática das doenças, vale destacar, as pesquisas que estão sendo desenvolvidas e apresentadas nesta edição: o estudo que identificou o efeito citopático do vírus zika em cultura de células em laboratório, que traz o debate se 


\section{HISTÓRIA}

VÍRUS ZIKA NA HISTÓRIA DAS DOENÇAS: DA MALFORMAÇÃO NA GESTAÇÃO ÀS POLÍTICAS PÚBLICAS NO CAMPO DA SAÚDE REPRODUTIVA DA MULHER

Reynaldo José Loio Alves

vírus está ativo e do possível potencial de transmissão da infecção pela saliva e urina; em outra pesquisa, que abrange o desafio do Brasil em eliminar a dengue, é estudado o potencial da bactéria Wolbachia de reduzir a transmissão do vírus Zika pelo mosquito Aedes aegypti. Os demais estudos caracterizam o papel da Fundação Oswaldo Cruz (Fiocruz) nos esforços e ações em torno da identificação e diagnóstico do vírus, da produção vacinal, de ações voltadas para os vetores e transmissores e, de pesquisas que relacionam o vírus Zika à ocorrência de microcefalia em bebês de mães infectadas, lembrando que um dos focos deste trabalho, será analisar dois estudos apresentados na Revista de Manguinhos e que está direcionada a temática.

O segundo aborda as fontes acerca do campo de respostas, ações e políticas públicas do Ministério da Saúde em relação ao contexto epidêmico, no qual foram selecionados documentos que são parte integrante da agenda de combate ao vírus Zika e à microcefalia, que são: o Protocolo de Atenção à saúde e resposta à ocorrência de Microcefalia relacionada à infecção pelo Vírus Zika (2015) e a Cartilha de Informação ao público - Vírus Zika, volume 2 (2016).

Assim, no Protocolo direcionado aos profissionais de saúde envolvidos, priorizamos alguns trechos que se referem aos objetivos do documento, as manifestações clínicas da infecção pelo vírus Zika e sua associação com a microcefalia, além do foco importante desta análise, que é a atenção à saúde das mulheres frente às políticas públicas. Na cartilha de informação sobre o vírus direcionada ao público, verificamos algumas estratégias de comunicação do setor de saúde e a convenção/difusão de saberes, ações e políticas sobre os assuntos relacionados ao Zika e a microcefalia.

O terceiro, por sua vez, está relacionado ao campo de história das doenças, onde contextualiza saúde e doença discutindo os impactos, diálogos e lacunas entre os campos analisados, principalmente, pelos debates sobre a necessidade de "revisão" dos direitos e de políticas públicas voltadas à saúde reprodutiva da mulher. Portanto, entende-se que o fio "condutor" para os debates, giram em torno da problemática da epidemia do vírus Zika e da ocorrência de microcefalia.

VÍRUS ZIKA E MICROCEFALIA: DEFINIÇÃO, ASSOCIAÇÃO, DOENÇAS E DIMENSÃO MÉDICO-CIENTÍFICA 


\section{HISTÓRIA}

VÍRUS ZIKA NA HISTÓRIA DAS DOENÇAS: DA MALFORMAÇÃO NA GESTAÇÃO ÀS POLÍTICAS PÚBLICAS NO CAMPO DA SAÚDE REPRODUTIVA DA MULHER

Reynaldo José Loio Alves

A discussão desenvolvida neste tópico, visa adentrar o contexto em torno dos conceitos de saúde e doença nas sociedades contemporâneas, principalmente, na medida em que estes representam campos mutáveis e que passam por transformações frequentes na história. A definição de doença engloba aspectos multifacetados que dialogam em torno da sua definição, o trabalho busca-se elucidar os argumentos apresentados por Rosenberg (1997, p.14), no que tange a doença enquanto diagnóstico do social, ou seja, a doença desempenhando o papel de ajudar a enquadrar debates sobre a sociedade e política social, ou um enquadramento do social a partir da utilização da doença. A doença tornou-se, em alguma medida, a ocasião e a agenda para a preocupação do discurso de inter-relação da política do Estado, da responsabilidade médica e da culpabilidade individual. Desse modo, Rosenberg (1997, p.16) mostra que a experiência individual da doença, a influência da cultura sobre as definições desta e do papel do Estado na definição e resposta à doença são fatores importantes.

Conforme defende Herzlich (2004, p.384), as ideias de saúde e doença pertencem tanto ao domínio público, quanto ao privado. Contudo, há uma crescente importância da saúde na contemporaneidade, e uma ênfase que está transferindo a "responsabilidade" pela saúde do domínio público para o privado. Ainda sobre a ideia de doença, (HERZLICH, 2005, p. 66) argumenta que por ser um evento que ameaça ou modifica, às vezes irremediavelmente, nossa vida individual, nossa inserção social e, portanto, o equilíbrio coletivo, a doença engendra sempre uma necessidade de discurso, a necessidade de uma interpretação complexa e contínua da sociedade inteira. Sendo assim, podemos contextualizar a realidade expressa pelos discursos da mídia e do Estado na responsabilização do indivíduo no que se refere à eclosão de um contexto epidêmico, quer seja nas medidas preventivas de combate ao mosquito e/ou da própria proliferação da doença.

O aparecimento de um novo vírus do gênero Flavivírus no decorrer de 2015, transmitido principalmente pelo mosquito Aedes Aegypti gerou um contexto epidêmico, cujo destaque se deu pela ocorrência de microcefalia nos bebês de mulheres infectadas durante a gravidez. Esses aspectos fizeram com que a epidemia se tornasse uma grave questão de saúde pública nacional. Sob a orientação de diferentes frentes, ocorreu uma mobilização nacional em torno da epidemia do Zika, 
VÍRUS ZIKA NA HISTÓRIA DAS DOENÇAS: DA MALFORMAÇÃO NA GESTAÇÃO ÀS POLÍTICAS PÚBLICAS NO CAMPO DA SAÚDE REPRODUTIVA DA MULHER

Reynaldo José Loio Alves

que incluiu a criação do Plano Nacional de Enfrentamento à Microcefalia, envolvendo vários ministérios, instituições de pesquisa e sociedade. Intensificaram-se ações, debates e estudos científicos visando o combate ao mosquito, a definição da doença e a confirmação da associação entre o vírus e a ocorrência da microcefalia.

Segundo informações do Ministério da Saúde (2015), os estudos, protocolos e diretrizes que abordam o vírus Zika sinalizam que a infecção afeta todos os grupos etários, de ambos os sexos e à luz do conhecimento atual, é uma doença febril aguda, que leva a uma baixa necessidade de hospitalização e que, via de regra, não era associada a complicações. Quando sintomática, a infecção pelo vírus Zika pode cursar com febre baixa (ou, eventualmente, sem febre). Os sinais e sintomas ocasionados pelo vírus Zika, em comparação aos de outras doenças exantemáticas (dengue, chikungunya e sarampo), incluem um quadro exantemático mais acentuado e hiperemia conjuntival, sem alteração significativa na contagem de leucócitos e plaquetas. $^{2}$

A etiologia do vírus em questão se tornou um tema de saúde global nos primeiros meses de 2016, sendo explorada e debatida por diferentes estudos, instituições e coletivos de pensamento ${ }^{3}$. Os estudos são diversificados, vale ressaltar, os que tangem a estrutura, a ação do vírus, o mapeamento do genoma, as possibilidades de transmissão, os vetores em potencial e, principalmente, a associação entre o vírus e a ocorrência de microcefalia. Estudos apontaram que, a estrutura do vírus Zika é parecida com o da dengue e da febre amarela, trata-se de doenças da família de Flavivírus, um estudo específico da Universidade Purdue e dos Institutos Nacionais de Saúde dos Estados Unidos (NIH), publicado em 2016 na Revista Science, identificou que uma possível diferença entre o vírus Zika dos outros flavivírus, esteja na proteína-chave da superfície, que tem a capacidade de invadir o sistema nervoso de um feto em desenvolvimento, levando à microcefalia.

\footnotetext{
${ }^{2}$ Nota do Protocolo de atenção à saúde e resposta à ocorrência de microcefalia relacionada à infecção pelo vírus Zika. Secretaria de Atenção à Saúde - Brasília: Ministério da Saúde, 2015. 49p.. : il.

${ }^{3}$ Conceito de Ludwik Fleck presente na obra Gênese e desenvolvimento de um fato científico (2010), entende-se coletivo de pensamento como, a comunidade de pessoas que trocam pensamentos ou se encontram numa situação de influência recíproca de pensamentos, tendo em cada uma dessas pessoas, um portador do desenvolvimento histórico de uma área de pensamento, de um determinado estado do saber e da cultura, ou seja, de um estilo específico de pensamento. 
VÍRUS ZIKA NA HISTÓRIA DAS DOENÇAS: DA MALFORMAÇÃO NA GESTAÇÃO ÀS POLÍTICAS PÚBLICAS NO CAMPO DA SAÚDE REPRODUTIVA DA MULHER

Reynaldo José Loio Alves

O Brasil foi um dos países pioneiros na promoção de debates e estudos, publicados na literatura científica internacional sobre a implicação da microcefalia relacionada ao vírus Zika. A celeridade relacional entre o Zika e o surto de microcefalia, teve como importante fator, o subsídio de informações da vigilância epidemiológica para a identificação do vírus em amostras de bebês com malformações. Os estudos epidemiológicos, clínicos e laboratoriais realizados no país, tiveram papel fundamental para a comprovação dessa relação. O trabalho dos pesquisadores brasileiros, também resultou em importante desenvolvimento tecnológico, a exemplo dos testes diagnósticos. ${ }^{4}$

A associação entre as doenças se apresentou como tema de debate a nível internacional em fevereiro de 2016, principalmente, quando a Organização Mundial de Saúde (OMS) declarou o evento como Emergência de Saúde Pública de Importância Internacional (ESPII), reconhecendo a possível associação. Essa situação que foi posteriormente confirmada, devido aos estudos em diversos campos do conhecimento e ao forte consenso científico em torno da relação causal entre o vírus e a ocorrência de microcefalia.

A epidemia de Zika vírus e a ocorrência da microcefalia representam um exemplo do processo de "cooperação" internacional para combate a novos eventos no campo de saúde pública, tanto na dimensão médico-científica, quanto na políticoeconômica. Dessa forma, é possível pensar alguns aspectos do debate mais amplo em torno do vírus Zika e da perspectiva de 'saúde global', essa por sua vez, se apresenta como uma resposta racional a novos eventos e ameaçadores na saúde pública, tais como epidemias internacionais, que atingem tanto países ricos como países pobres. Essa expressão emergiu como parte de um processo histórico e político mais amplo, em meio a um debate ainda não resolvido sobre a direção que deve tomar a saúde pública, no contexto de uma ordem mundial neoliberal, no qual a Organização Mundial de Saúde viu seu papel, antes dominante, ser desafiado, e começou a reposicionar-se no âmbito de um conjunto de alianças de poder em transformação (BROW; CUETO; FEE, 2006, p. 641).

\footnotetext{
${ }^{4}$ Editorial publicado na Revista do Sistema Único de Saúde do Brasil (RESS) com o tema: Pesquisa e desenvolvimento para o enfrentamento da epidemia pelo vírus Zika e suas complicações. Epidemiologia e Serviços de Saúde. Brasília, 25(2): 231-232, abr-jun 2016. 


\section{HISTÓRIA}

VÍRUS ZIKA NA HISTÓRIA DAS DOENÇAS: DA MALFORMAÇÃO NA GESTAÇÃO ÀS POLÍTICAS PÚBLICAS NO CAMPO DA SAÚDE REPRODUTIVA DA MULHER

Reynaldo José Loio Alves

O quadro epidemiológico brasileiro em relação ao vírus Zika se agravou devido ao aumento da ocorrência de microcefalia em bebês, principalmente, nos estados de Pernambuco, Paraíba, Bahia e Rio Grande do Norte (DINIZ, 2016, p.1). O Ministério da Saúde divulgou registros periódicos de monitoramento de casos notificados, confirmados e descartados de Zika e da microcefalia. Além disso, foram adotadas medidas em torno da questão, diversos estudos e pesquisas, ações de combate ao mosquito e à alusão de protocolos, diretrizes e cartilhas. Essas medidas buscam orientar profissionais de saúde, sociedade, mulheres em idade fértil e gestantes, em específico, devido à necessidade de acompanhamento no pré-natal e à associação com casos de microcefalia em recém-nascidos.

Podemos observar os dados apresentados pela Vigilância Epidemiológica, que foi confirmada a transmissão autóctone de febre pelo vírus Zika no país a partir de abril de 2015. Em 2016, os dados da Semana Epidemiológica 23 registraram 165.932 casos prováveis de febre pelo vírus Zika no país (taxa de incidência de 81,2 casos/100 mil hab.), distribuídos em 1.850 municípios, dos quais 66.180 foram confirmados. ${ }^{5}$

Conforme dados apresentados até 30 de junho de 2016, foi confirmada a transmissão vetorial do vírus Zika em 61 países, sendo 40 (65\%) nas Américas. A população mundial exposta ao vírus é de 1.340 .312 .410 pessoas, das quais $15 \%$ são brasileiros. Em relação ao monitoramento dos casos de microcefalia, até 02 de julho de 2016 (SE 26), 8.301 casos foram notificados, segundo as definições do Protocolo de vigilância (recém-nascido, natimorto, abortamento ou feto). Desses, $3.130(37,7 \%)$ casos permanecem em investigação e 5.171 casos foram investigados e classificados, sendo 1.656 confirmados para microcefalia e/ou alteração do SNC sugestivos de infecção congênita e 3.515 descartados. Do total de 8.301 casos notificados, 334 (4\%) casos evoluíram para óbito fetal ou neonatal. Dos 334 óbitos fetais ou neonatais notificados, 184 (55,1\%) permanecem em investigação, 92 (27,5\%) foram

\footnotetext{
${ }^{5}$ Boletim epidemiológico de Monitoramento dos casos de dengue, febre de chikungunya e febre pelo vírus Zika até a Semana Epidemiológica 23,2016. (3/1/2016 a 11/06/2016), último boletim divulgado. http://portalsaude.saude.gov.br/images/pdf/2016/julho/15/2016-boletim-epi-n28-dengue-chik-zikase23.pdf
} 


\section{HISTÓRIA}

VÍRUS ZIKA NA HISTÓRIA DAS DOENÇAS: DA MALFORMAÇÃO NA GESTAÇÃO ÀS POLÍTICAS PÚBLICAS NO CAMPO DA SAÚDE REPRODUTIVA DA MULHER

Reynaldo José Loio Alves

confirmados para microcefalia e/ou alteração do SNC sugestivos de infecção congênita e $57(17,4 \%)$ foram descartados. ${ }^{6}$

A microcefalia tem características que envolvem a malformação do cérebro e o comprometimento de funções neuropsicomotoras. Atualmente, está sendo amplamente debatida devido ao aumento de casos relacionados com a epidemia do vírus Zika, ambas emergem como protagonistas neste campo de debates, que englobam as ações de saúde pública, o campo científico e uma turbulenta conjuntura político, social e econômico.

A microcefalia é uma malformação congênita em que o cérebro não se desenvolve de maneira adequada. É caracterizada por um perímetro cefálico inferior ao esperado para a idade e sexo e, dependendo de sua etiologia, pode ser associada a malformações estruturais do cérebro ou ser secundária a causas diversas. A ocorrência de malformação, por si só, não significa que ocorram alterações motoras ou mentais. Crianças com perímetro cefálico abaixo da média podem ser cognitivamente normais, sobretudo se a microcefalia for de origem familiar. Contudo, a maioria dos casos de microcefalia é acompanhada de alterações motoras e cognitivas que variam de acordo com o grau de acometimento cerebral. Em geral, as crianças apresentam atraso no desenvolvimento neuropsicomotor, com acometimento motor e cognitivo relevante e, em alguns casos, as funções sensitivas (audição e visão) também são comprometidas. O comprometimento cognitivo ocorre em cerca de $90 \%$ dos casos. ${ }^{7}$

Segundo os protocolos e diretrizes publicados pelo Ministério da Saúde sobre a microcefalia, é importante ressaltar que as possíveis classificações se dão em conformidade com o tempo de seu início, a microcefalia congênita: está presente ao nascimento e é às vezes chamada de "microcefalia primária"; porém, como este termo se refere a um fenótipo particular de microcefalia, deve-se usar preferencialmente "microcefalia congênita"; e a microcefalia pós-natal: refere-se à falha de crescimento

\footnotetext{
${ }^{6}$ Informe epidemiológico $\mathrm{n}^{\circ}$ 33,(SE) 26/2016 (26/06 A 02/07/2016). Monitoramento dos casos de microcefalia no

Brasil.

http://combateaedes.saude.gov.br/images/pdf/informe microcefalia_epidemiologico33.pdf

${ }^{7}$ Nota sobre a microcefalia no Protocolo de atenção à saúde e resposta à ocorrência de microcefalia relacionada à infecção pelo vírus Zika. Secretaria de Atenção à Saúde - Brasília: Ministério da Saúde, 2015. 49p... : il.
} 
VÍRUS ZIKA NA HISTÓRIA DAS DOENÇAS: DA MALFORMAÇÃO NA GESTAÇÃO ÀS POLÍTICAS PÚBLICAS NO CAMPO DA SAÚDE REPRODUTIVA DA MULHER

Reynaldo José Loio Alves

normal do perímetro cefálico após o nascimento, ou seja, o cérebro é normal ao nascimento; por isso é também chamada de "microcefalia secundária".

Além disso, é fundamental contextualizar as possíveis lacunas em torno da temática da epidemia, visto que sua caracterização e discursos se constituem por meio de diferentes visões, consensos e controvérsias, tanto no campo da produção científica e clínica, quanto das políticas de saúde pública.

O rápido processo de desenvolvimento da produção e publicação científica nos permitiu enxergar uma clara articulação sobre o assunto. As informações descritas na Revista Manguinhos, estimou uma rede de 300 pesquisadores brasileiros que estavam se dedicando ao estudo de aspectos relacionados ao vírus e seus impactos para a saúde pública brasileira. Dessa forma, esses "grupos" trouxeram expressivos avanços e conhecimento sobre o vírus, mas os debates e discursos correntes demonstraram a necessidade de ações e estudos adicionais a fim de que as lacunas sejam preenchidas e que novos entendimentos sejam convencionados sobre o vírus Zika, tal como, seus mecanismos de infecção, sua relação com o(s) vetor(es), as potenciais complicações nas diversas etapas do ciclo de vida, além de outras questões importantes para a prevenção, o controle e o tratamento da doença.

No contexto brasileiro, os desafios são ainda maiores, principalmente por uma conjuntura desfavorável, em que diversos fatores incidem num quadro epidêmico além da capacidade de resposta das ações estatais e de investimentos para produção de conhecimento científico local. Tal como, problemas de saneamento básico, disparidades geográficas entre as localidades afetadas, atores sociais envolvidos, condições de desigualdades socioeconômicas, precariedade na estrutura e dificuldade de acesso aos serviços de saúde, além da necessidade de revisão de direitos e de políticas públicas de saúde reprodutiva da mulher.

SAÚDE REPRODUTIVA: DAS POLÍTICAS PÚBLICAS À REVISÃO DOS DIREITOS DA MULHER

O tópico desenvolvido a seguir, explicita alguns aspectos selecionados nos materiais apresentados. Desse modo, serão analisadas questões fundamentais ao campo das políticas públicas e as estratégias de comunicação do setor de saúde em 


\section{HISTÓRIA}

VÍRUS ZIKA NA HISTÓRIA DAS DOENÇAS: DA MALFORMAÇÃO NA GESTAÇÃO ÀS POLÍTICAS PÚBLICAS NO CAMPO DA SAÚDE REPRODUTIVA DA MULHER

Reynaldo José Loio Alves

relação às doenças. Busca-se aprofundar críticas e reflexões às questões explicitadas no protocolo e na cartilha, no que tange ao debate (ou a falta de), em torno da revisão de diretos e de informações sobre o aborto nos casos de microcefalia e de ações no campo da saúde reprodutiva da mulher.

Sobre a escrita da história, Michel de Certeau (1982 apud Garcia 2015, p.4), nos traz a questão do "não-dito", e problematiza o silêncio das fontes, ou seja, que este silêncio é tão importante quanto o encontro de vestígios que podem criar versões do dito. Nesse sentido, o material explorado sobre o Zika nos demonstra o "não-dito" sobre os direitos da mulher em relação à saúde reprodutiva e às informações sobre aborto previsto em lei. No que tange às ações expressas em políticas públicas em relação à temática, percebemos a omissão do Estado frente a garantia dos direitos dessas mulheres, seja no campo do acesso, da informação e/ou da assistência pós diagnóstico/ocorrência da microcefalia.

A cartilha destinada ao público traz as estratégias de comunicação do governo acerca do vírus Zika e está estruturada em tópicos sobre a prevenção/proteção, cuidados e informações. Os assuntos abordados se relacionam com o combate ao mosquito, tendo um exemplo de frase emblemática "Se o mosquito pode matar, ele não pode nascer". Especificamente, relata a possibilidade de orientação sobre planejamento reprodutivo e/ou métodos contraceptivos nas Unidades Básicas de Saúde, direcionado às mulheres em idade fértil.

Nos tópicos direcionados às gestantes e aos cuidados com recém-nascidos com ou sem microcefalia, enfatiza-se a necessidade de acompanhamento do prénatal em todos os períodos da gestação, a realização das vacinas e o alerta dos possíveis sintomas relacionados ao vírus. Sobre esses pontos, coloca-se a reflexão, em que medida as mulheres das áreas mais afetadas possuem acesso aos serviços de saúde e às informações das campanhas e cartilhas? Como estão/são as estruturas e os recursos materiais e operacionais das Unidades nas áreas afetadas?

O Protocolo de Atenção à saúde e resposta à ocorrência de Microcefalia relacionada à infecção pelo Vírus Zika (2015) visa nortear os profissionais da atenção à saúde, por meio de orientações e diretrizes, direcionando ações de prevenção da infecção pelo vírus Zika em mulheres em idade fértil e gestantes e, a atenção no prénatal, parto e nascimento, a assistência e estimulação precoce dos nascidos com 


\section{HISTÓRIA}

VÍRUS ZIKA NA HISTÓRIA DAS DOENÇAS: DA MALFORMAÇÃO NA GESTAÇÃO ÀS POLÍTICAS PÚBLICAS NO CAMPO DA SAÚDE REPRODUTIVA DA MULHER

Reynaldo José Loio Alves

microcefalia, em todo o território nacional. Sob a ótica da atenção à saúde da mulher, o protocolo enfatiza ações voltadas ao planejamento reprodutivo, que incluem prénatal, atenção ao parto, nascimento e puerpério, além da atenção à saúde do recémnascido (RN), lactante e criança com microcefalia.

Os assuntos abordados na cartilha sintetizam e se relacionam com as orientações expressas no Protocolo de Atenção à saúde. Dessa forma, é importante contextualizar alguns pontos debatidos nestes documentos, a fim de aprofundar as questões sobre a saúde reprodutiva da mulher frente às estratégias e ações de saúde pública no contexto da epidemia de Zika.

Conforme o Protocolo (2015), as equipes de saúde devem reforçar as ações de oferta e ampliação do acesso aos métodos contraceptivos para a população, com atenção especial ao acompanhamento das mulheres de seu território que estão em idade fértil. O protocolo ressalta que o Ministério da Saúde "distribui" para os municípios brasileiros, métodos contraceptivos para disponibilização gratuita nas Unidades Básicas de Saúde. No entanto, sabemos que a promoção desses métodos não funcionam de forma igualitária em todas as regiões, a falta de insumos nas unidades é recorrente. Além disso, a atenção à saúde sexual e reprodutiva vai além da oferta de métodos e técnicas para a concepção, e a anticoncepção inclui a oferta de informações e acompanhamento, sob o enfoque de direitos, em um contexto de escolha livre e informada, algo não explorado pelo protocolo.

O tópico que orienta as ações no campo específico do planejamento reprodutivo de atenção à saúde da mulher nos permite ver as lacunas presentes no documento acerca de debates mais amplos sobre a estrutura da saúde pública, os direitos das mulheres no campo da saúde reprodutiva e do acesso aos serviços de saúde. Por exemplo, no que tange às questões relatadas acima, o documento reconhece a amplitude da atenção à saúde sexual e reprodutiva para além da oferta de métodos contraceptivos, mas parece restringir o escopo apenas às informações e orientações a essas mulheres, sobre a prevenção do vírus Zika e dos cuidados necessários para se evitar a infecção durante o período gestacional.

O Protocolo apresenta falhas em não abordar e orientar os profissionais e as mulheres sobre o aborto previsto em lei, ou ainda sobre o método emergencial de contracepção (BAUM et. al. 2016, p. 2). Não há reconhecimento sobre as falhas 


\section{HISTÓRIA}

VÍRUS ZIKA NA HISTÓRIA DAS DOENÇAS: DA MALFORMAÇÃO NA GESTAÇÃO ÀS POLÍTICAS PÚBLICAS NO CAMPO DA SAÚDE REPRODUTIVA DA MULHER

Reynaldo José Loio Alves

estruturais nos contextos locais que podem potencializar o caráter epidêmico do vírus Zika e à ocorrência de microcefalia, como por exemplo, a dificuldade de locomoção e acesso aos serviços de saúde, a negligência e omissão de informações e o acesso limitado a métodos contraceptivos. As mulheres pobres e nordestinas, são uma parte considerável do público afetado pelo vírus e vivem nas localidades mais afetadas pela epidemia (rurais e periferias) e se encontram em condição de vulnerabilidade socioeconômica (DINIZ, 2016, p.1).

Como vem sendo amplamente debatido em artigos sobre o vírus Zika e a gravidez, o Protocolo deixa a desejar por não abordar questões cruciais que estão relacionadas ao campo de saúde reprodutiva da mulher. Como já foi dito, há omissão em relação à questão do aborto, uma prática comum no Brasil. Em relação a isso, podemos destacar que a prática afeta de forma desproporcional as mulheres, que por se encontrarem em condição de vulnerabilidade socioeconômica são as maiores vítimas, seja pelos riscos à saúde e/ou pela criminalização da prática. Atualmente, o aborto inseguro representa um grave problema de saúde pública, gerando cerca de 250 mil/ano atendimentos em emergências por conta de complicações após a prática (BAUM et. al. 2016, p. 2).

As incertezas sobre os efeitos da infecção do vírus Zika no desenvolvimento fetal pode ser um fator que gere aumento do número de abortos inseguros. Desse modo, o Protocolo perde a oportunidade de informar e orientar os profissionais de saúde e consequentemente, as mulheres, a fim de reduzir possíveis riscos e danos relacionados ao aborto.

As lacunas do Protocolo sobre os riscos do aborto inseguro no contexto da epidemia de Zika é uma falha que impede o acesso à saúde com igualdade, mas também aponta para a negligência governamental na efetivação de medidas de proteção dos direitos humanos das mulheres, violando as normas de saúde global e de direitos humanos internacionais (BAUM et. al. 2016, p. 2). Nesse sentido, as lacunas descritas, não só limitam o campo de ações em saúde, da orientação aos profissionais sobre a temática, como negligenciam informações e violam os direitos à saúde, previstos na Constituição Federal (1988), rompendo pilares do direito à saúde, à vida, à igualdade e à autodeterminação e autonomia reprodutiva, comprometendo a autonomia da mulher em relação à sua saúde reprodutiva. 


\section{HISTÓRIA}

VÍRUS ZIKA NA HISTÓRIA DAS DOENÇAS: DA MALFORMAÇÃO NA GESTAÇÃO ÀS POLÍTICAS PÚBLICAS NO CAMPO DA SAÚDE REPRODUTIVA DA MULHER

Reynaldo José Loio Alves

A antropóloga Débora Diniz tem colaborado para ampliação do debate acerca das questões sociais presentes no cerne da epidemia de vírus Zika, principalmente, no que refere a realidade da saúde reprodutiva da mulher. Nesse sentido, podemos citar o documentário Zika produzido entre fevereiro e abril de 2016, onde são reunidas histórias de gestantes e mães afetadas pela disseminação do vírus na região Nordeste. Sendo assim, o documentário sintetiza e evidencia que as mulheres são o rosto, a cor, a classe social, a região e o retrato da desigualdade social presente nessa epidemia, assim como nos denuncia as diferentes formas que a doença, a epidemia e as desigualdades atingem as mulheres.

O diálogo entre os campos apresentados no trabalho traz algumas questões importantes à historiografia e a outros campos de conhecimento. Sendo assim, as fontes e o material bibliográfico analisados reafirmam a hipótese central de que as políticas públicas e as ações estatais não apresentaram resultados efetivos em relação ao enfrentamento da epidemia. Podemos ver alguns exemplos de que as ações não avançaram de forma devida na assistência aos atores sociais afetados pela primeira geração da epidemia do vírus: o Estado não criou nenhuma política específica de assistência às mulheres com bebês que convivem com a síndrome neurológica, as dificuldades operacionais são latentes no atendimento as famílias que precisam de transporte periódico para o tratamento e acompanhamento nos centros urbanos, não houve mudanças na política de assistência social e há inúmeros casos de mães que não recebem qualquer benefício social para cuidarem de seus filhos.

No campo de ações e políticas públicas que possam minimizar as epidemias no futuro recente, podemos citar que não houve alterações significativas por parte do Estado acerca das questões que envolvem a segunda geração de atores sociais afetados pela epidemia. Por exemplo, o protocolo de enfrentamento não foi atualizado para síndrome neurológica, não houve revisão de questões sobre a saúde reprodutiva da mulher e os debates e informações sobre o aborto previsto em lei não foram abordados. A negligência dessas e de outras questões demonstram que o Estado ainda não promoveu ações que dessem respostas positivas à população, como no caso do planejamento familiar, não se buscou a prevenção para as que queriam engravidar, nem para as que não queriam, além disso se ignorou as mulheres que tiveram filhos com a síndrome neurológica (DINIZ, 2016, p. 3). 
VÍRUS ZIKA NA HISTÓRIA DAS DOENÇAS: DA MALFORMAÇÃO NA GESTAÇÃO ÀS POLÍTICAS PÚBLICAS NO CAMPO DA SAÚDE REPRODUTIVA DA MULHER

\section{CONCLUSÃO}

Reynaldo José Loio Alves

O trabalho buscou contextualizar a epidemia através da abordagem da historiografia das doenças, mesmo não havendo um aprofundamento sobre as questões estruturais e as formas de acesso aos serviços de saúde específicas do contexto epidêmico ocorrido recentemente, alguns pontos elucidam a importância dos debates sobre o problema. Primeiramente, porque trata-se de uma doença com alta potencialidade de transmissão (vetor que voa, transmissibilidade sexual, transfusão sanguínea, amamentação, sangue, urina), e pouco ou quase nada se sabe da capacidade de transmissão vertical do vírus. Segundo ponto, a doença tem servido de exemplo para demonstrar a incapacidade das ações e políticas públicas no contexto epidêmico, sobretudo por negligenciar uma agenda político-institucional que aprofunde e revise temas ligados à saúde reprodutiva da mulher.

A partir das especificidades apresentadas pela epidemia, podemos refletir algumas lições e possibilidades de estudo na historiografia das doenças. Portanto, os debates em torno do vírus Zika e da ocorrência de síndrome neurológica, principalmente pelo desenvolvimento da microcefalia, nos abrem caminhos para entender o quadro de uma "doença social" que se apresenta emergindo neste contexto.

Desse modo, a análise articula o conceito em torno da doença como possível diagnóstico do social, e mais do que isso, percebemos que o contorno da epidemia demonstra a incapacidade das ações do Estado em promover políticas públicas ao enfretamento do problema. É preciso promover uma agenda político-institucional que vá além do combate ao mosquito, onde as mulheres estejam no centro dessas ações, seja no campo da prevenção, da assistência ou na própria revisão das questões da saúde sexual e reprodutiva.

Sob a ótica da abordagem historiográfica, podemos dizer que o contexto experimentado na atual epidemia do vírus Zika apresenta uma gama de objetos e perspectivas de análise, seja na dimensão da saúde e da doença, das políticas públicas ou da produção e circulação de conhecimento médico-científico. A ocorrência da síndrome neurológica, como por exemplo nos casos de microcefalia e/ou de alterações no Sistema Nervoso Central relacionada à infecção do Zika emerge como 
VÍRUS ZIKA NA HISTÓRIA DAS DOENÇAS: DA MALFORMAÇÃO NA GESTAÇÃO ÀS POLÍTICAS PÚBLICAS NO CAMPO DA SAÚDE REPRODUTIVA DA MULHER

Reynaldo José Loio Alves

grave questão de saúde pública. Se por um lado, a celeridade na produção de conhecimento médico-científico demonstra os avanços e sucessos nas ações, por outro, a (in)capacidade do governo em agir de forma eficiente, eficaz e efetiva, denuncia o contexto das políticas públicas de prevenção, controle e assistência em relação as doenças e ao contexto epidêmico apresentado.

No contexto brasileiro, os desafios são grandes, principalmente pela conjuntura desfavorável, em que diversos fatores incidem num quadro epidêmico além da capacidade de resposta das ações estatais e de investimentos para produção de conhecimento científico local, tal como, problemas de saneamento, disparidades geográficas entre as localidades afetadas, desigualdades socioeconômicas, precariedade na estrutura e dificuldade de acesso aos serviços de saúde.

Os dados epidemiológicos e as controvérsias científicas sobre as doenças não podem servir para esquecer o abandono das mulheres que tiveram bebês com síndrome neurológica, principalmente a microcefalia, cujas ações do Estado não acompanham o ritmo dos percalços da vida cotidiana. Este trabalho abre a possibilidade para novos diálogos e pesquisas sobre a representação social da doença no campo de experiências vivenciadas pelas diferentes gerações de mães que tiveram o vírus e consequentemente, bebês com microcefalia. Sendo assim, o trabalho aponta para a necessidade de aprofundar algumas questões relacionadas à contextualização socioeconômica, às relações de gênero, discriminação sexual e a representação sob a ótica das "mães Zika", no sentido de contribuir para debates amplos com vistas à revisão e cumprimento de direitos em relação às políticas públicas de atenção em saúde reprodutiva da mulher. Portanto, corroborando com a afirmação de (BAUM, et. al. 2016, p.3), o Zika é um alerta, e chegou a hora de leis e políticas de saúde respeitarem os direitos humanos e a autonomia das mulheres sobre seus corpos e suas vidas.

\section{FONTES DIGITAIS E IMPRESSAS}

Brasil. Ministério da Saúde. Cartilha de Informações ao público - vírus Zika. Ministério da Saúde, Secretaria de Atenção à Saúde - Brasília: Ministério da Saúde, 2016. v. 2, p.6. Ver em: http://combateaedes.saude.gov.br/images/conteudo/cartilha- 


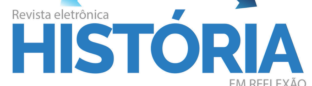

VÍRUS ZIKA NA HISTÓRIA DAS DOENÇAS: DA MALFORMAÇÃO NA GESTAÇÃO ÀS POLÍTICAS PÚBLICAS NO CAMPO DA SAÚDE REPRODUTIVA DA MULHER

Reynaldo José Loio Alves

Brasil. Ministério da Saúde. Secretaria de Atenção à Saúde. Protocolo de atenção à saúde e resposta à ocorrência de microcefalia relacionada à infecção pelo vírus Zika. Ministério da Saúde, Secretaria de Atenção à Saúde - Brasília: Ministério da Saúde, 2015. 49p.. : il. Modo de acesso: www.saude.gov.br/svs

REVISTA DE MANGUINHOS. Rio de Janeiro: Coordenadoria de comunicação social/Presidência Fiocruz. v. 34: 62p. maio 2016.

\section{REFERÊNCIAS}

ARMUS, Diego. Discursos, políticas y experiencias en la historia de las enfermedades. In. BIENART, Carolina. Historia de la salud y la enfermedad bajo la lupa de las ciencias sociales. Buenos Aires: Biblios. 2014.

BAUM, Paige et. al. Garantindo uma resposta do setor de saúde com foco nos direitos das mulheres afetadas pelo vírus Zika. Cad. Saúde Pública, Rio de Janeiro, 32(5):e00064416, maio 2016. Ver em: http://dx.doi.org/10.1590/0102-311X00064416

BROWN, Th. M.; CUETO, M.; FEE, E.: A transição de saúde pública 'internacional' para global' e a Organização Mundial da Saúde. História, Ciências, Saúde Manguinhos, v. 13, n. 3, p. 623-47, jul.-set. 2006.

DINIZ, Debora. Vírus Zika e mulheres. Cad. Saúde Pública, Rio de Janeiro, 32(5):e00046316, maio 2016. Ver em: http://dx.doi.org/10.1590/0102-311X00046316

DUARTE, Elisete; GARCIA, Leila Posenato. Pesquisa e desenvolvimento para o enfrentamento da epidemia pelo vírus Zika e suas complicações. Epidemiol. Serv. Saude, Brasília. 25(2):231-232, abr-jun 2016 Ver em: http://doi:10.5123/S167949742016000200001

FLECK, Ludwik. Gênese e Desenvolvimento de um Fato Científico. Belo Horizonte: Fabrefactum Editora. 2010. 


\section{HISTÓRIA}

VÍRUS ZIKA NA HISTÓRIA DAS DOENÇAS: DA MALFORMAÇÃO NA GESTAÇÃO ÀS POLÍTICAS PÚBLICAS NO CAMPO DA SAÚDE REPRODUTIVA DA MULHER

Reynaldo José Loio Alves

GARCIA, Tarcila Santos. A loucura impressa: uma representação social da loucura na mídia impressa, no contexto da Crise da Dinsam (1978-1982). Dissertação (Mestrado em História das Ciências e da Saúde) - COC/Fiocruz, Rio de Janeiro, 2015. $122 \mathrm{f}$.

HERZLICH, Claudine. A Problemática da Representação Social e sua Utilidade no Campo da Doença. Physis: Revista de Saúde Coletiva. Rio de Janeiro, 15(Suplemento): 57-70, 2005.

Saúde e doença no início do século XXI: entre a experiência privada e a esfera pública. Physis: Revista de Saúde Coletiva. Rio de Janeiro,14(2): 383-394, 2004.

HOCHMAN, Gilberto; Armus, Diego (orgs.). Introdução. In: Cuidar, controlar, curar ensaios históricos sobre a saúde e doença na América Latina e Caribe. Coleção História e Saúde. Rio de Janeiro: Editora Fiocruz, 2004, p. 11-28.

NASCIMENTO, Dilene Raimundo do. A representação social das doenças como peste. Boletim Eletrônico da Sociedade Brasileira de História da Ciência. B. 2, n.2. Março de 2014.

As pestes do século XX: tuberculose e Aids no Brasil, uma história comparada. Rio de Janeiro: Editora Fiocruz. 2005.

PITANGUY, Jacqueline. Os direitos reprodutivos das mulheres e a epidemia do Zika vírus. Cad. Saúde Pública. Rio de Janeiro, 32(5):e00066016, maio 2016. Ver em: http://dx.doi.org/10.1590/0102-311X00066016

LUZ, Kleber Giovanni; SANTOS, Glauco Igor Viana dos; VIEIRA, Renata de Magalhães. Febre pelo vírus Zika. Epidemiol. Serv. Saúde. Brasília, 24(4):785-788, out-dez 2015. Ver em: http://doi:10.5123/S1679-49742015000400021 
VÍRUS ZIKA NA HISTÓRIA DAS DOENÇAS: DA MALFORMAÇÃO NA GESTAÇÃO ÀS POLÍTICAS PÚBLICAS NO CAMPO DA SAÚDE REPRODUTIVA DA MULHER

Reynaldo José Loio Alves

ROSENBERG, Charles E. e GOLDEN, Janet (ed). Framing disease. Studies in cultural history. New Brunswick: Rutgers University Press,1997.

VALLE, Denise Valle; PIMENTA, Denise Nacif; AGUIAR, Raquel. Zika, dengue e chikungunya: desafios e questões. Epidemiol. Serv. Saude. Brasília, 25(2): 419-422, abr-jun 2016. Ver em: http://doi:10.5123/S1679-4974201600020002

ZIKA. Direção: Débora Diniz. Itinerante Filmes. 2016. (29m29s). Acesso: https://www.youtube.com/watch?v=m8tOpS515dA

Artigo recebido em 08/07/2017 Artigo aceito em 21/04/2018 